\title{
ESCOLARIZAÇÃO DE ESTUDANTES SURDOS E OS PROFISSIONAIS ENVOLVIDOS: o foco nos dispositivos legais brasileiros
}

\author{
Marily Oliveira Barbosa ${ }^{1}$
}

\section{RESUMO}

Várias conquistas já foram alcançadas em relação ao prescrito nos dispositivos legais brasileiros quanto à escolarização do estudante surdo: a garantia de uso da Língua de Sinais Brasileira (LIBRAS) em sala de aula; a presença de profissionais que façam uso desta língua; entre outras condições que auxiliam no aprendizado acadêmico na escola regular. Sob esse viés, este estudo busca analisar nos documentos legais brasileiros que tratam da educação de estudantes surdos quais tipos de apoio e quais profissionais deverão estar envolvidos no processo de escolarização e discutir sobre a formação dos profissionais no âmbito do prescrito. Este estudo é de cunho documental, por meio dos seguintes dispositivos legais: Lei $N^{\circ} 10.436$ (2002), Decreto No 5.626 (2005), Lei No 12.319 (2010) e Lei No 13.146 (2015). Esses dispositivos foram elencados por se relacionar diretamente a pessoa surda no quesito educacional. A análise de dados se deu por meio da análise de conteúdo do tipo temática. Enfatizamos que além da indispensável presença da língua de sinais em sala de aula e no ambiente escolar, como principal forma de comunicação do e com o estudante surdo, também é fundamental a presença de profissionais (instrutores e/ou professores surdos) que utilizem essa língua. Esses serão responsáveis tanto pelo ensino da língua de sinais para os estudantes surdos, quanto pela tradução e interpretação. A formação destes profissionais e a análise do prescrito é urgente para que a escolarização dos estudantes surdos ocorra de modo adequado às suas necessidades comunicativas e de aprendizagem.

Palavras-chave: Educação Especial. Estudantes surdos. Dispositivos legais.

\section{SCHOOLING OF STUDENTS WITH DEAFNESS AND PROFESSIONALS INVOLVED:}

\section{focus on Brazilian legal devices}

\begin{abstract}
Several achievements have already been achieved in relation to what is prescribed in Brazilian legal provisions regarding the schooling of students with deafness: the guarantee of use of the Brazilian Sign Language (LIBRAS) in the classroom; the

\footnotetext{
1 Doutora em Educação Especial (Universidade Federal de São Carlos). Professora dos cursos de graduação em Pedagogia e Enfermagem do Centro Universitário UNINASSAU e Professora do curso de graduação em Educação Física da Rede UNIRB Maceió. Orcid iD: https://orcid.org/0000-0001-8189-4234. E-mail: marilyufal@hotmail.com
} 
presence of professionals who make use of this language; among other conditions that aid in the academic learning in the regular school. Under this bias, this study seeks to analyze in the Brazilian legal documents dealing with the education of deaf students what types of support and which professionals should be involved in the schooling process and to discuss the training of professionals within the scope of the prescribed one. This study is documentary, through the following legal provisions: Law No. 10,436 (2002), Decree No. 5,626 (2005), Law No. 12,319 (2010) and Law No. 13,146 (2015). These devices were listed because they directly related the deaf person to the educational issue. Data analysis took place through content analysis. We emphasize that in addition to the indispensable presence of sign language in the classroom and in the school environment, as the main form of communication of and with the student with deafness, it is also essential the presence of professionals who use this language. These will be responsible for both sign language teaching for deaf students, and for translation and interpretation. The training of these professionals and the analysis of what is prescribed is urgent so that the schooling of students with deafness occurs in a way that suits their communicative and learning needs.

Keywords: Special Education. Students with deafness. Legal devices.

\section{ESCOLARIDADE DE ESTUDIANTES CON SORDERA Y PROFESIONALES}

\section{IMPLICADOS: enfoque en los dispositivos legales brasileños}

\section{RESUMEN}

Ya se han logrado varios logros en relación con lo prescrito en las disposiciones legales brasileñas sobre la escolarización de los estudiantes con sordera: la garantía de uso de LIBRAS en el aula; la presencia de profesionales que hacen uso de esta lengua; Entre otras condiciones que ayudan en el aprendizaje académico en la escuela. Bajo este sesgo, este estudio busca analizar en los documentos legales brasileños que tratan sobre la educación de los estudiantes sordos qué tipos de apoyo y qué profesionales deberían participar en el proceso de escolarización y discutir la capacitación de profesionales dentro del alcance de lo prescrito. Este estudio es documental, a través de las siguientes disposiciones legales: Ley $N^{0} 10.436$ (2002), Decreto 5.626 (2005), Ley 12.319 (2010) y Ley 13.146 (2015). Estos dispositivos se enumeraron porque relacionaban directamente a la persona sorda con el problema educativo. El análisis de los datos se realizó a través del análisis de contenido. Destacamos que además de la presencia indispensable de la lengua de señas en el aula, como la principal forma de comunicación de y con el estudiante con sordera, también es esencial la presencia de profesionales que utilizan esta lengua. Estos serán responsables tanto de la enseñanza de lenguaje de señas como de la traducción e interpretación. La capacitación de estos profesionales y el análisis de lo que se prescribe es urgente para que la escolarización de los estudiantes con sordera se realice de una manera que se adapte a sus necesidades comunicativas y de aprendizaje.

Palabras clave: Educación Especial. Estudiantes con sordera. Dispositivos legales. 


\section{INTRODUÇÃO}

Na atualidade, há inúmeras discussões sobre a escolarização de surdos. Em contexto amplo, é reafirmado o direito a escolarização em escola regular para todo e qualquer indivíduo, inclusive para as pessoas públicoalvo da educação especial, quais sejam: estudantes com deficiência, transtornos globais do desenvolvimento e altas habilidades/superdotação (BRASIL, 2009c). A partir da Constituição Federal do Brasil, foi firmado esse direito e reafirmado em diversos dispositivos legais, inclusive há posicionamento favorável à obrigatoriedade da escolarização em escolas, não mais em instituições especializadas como outrora ocorria no Estado brasileiro (BRASIL, 1988; 2002; 2005; 2010; 2011; 2015). Os direitos sociais conquistados são advindos da mobilização social que reivindicou os direitos prescritos (CAIADO, 2009), tais reinvindicações ganharam visibilidade e espaço político nos diversos segmentos sociais, fato esse que contribuiu para o alcance das políticas públicas relacionadas a pessoa surda.

O grupo de pessoas com deficiência tem direitos específicos na legislação brasileira. A pessoa surda é incluída nele por conta da deficiência sensorial auditiva, embora haja sujeitos surdos que não consideram essa peculiaridade como uma deficiência e sim uma condição do ser humano. Para além da discussão quanto à nomenclatura relacionada à deficiência ou individualidade humana, é preponderante ressaltar que há direitos previstos. Este estudo pondera que todo indivíduo deve ser visto como um ser histórico-cultural e que a sociedade necessita buscar um olhar para além das características biológicas e inatas do sujeito, visto que o indivíduo é formado a partir de suas interações com o meio (VIGOTSKI, 2010). Assim, o indivíduo surdo deve ser visto em totalidade e não apenas como possuidor do déficit auditivo enquanto deficiência.

O surdo, nos dispositivos legais brasileiros, é caracterizado pela perda auditiva e também pelos aspectos culturais que os interligam com o mundo e com a sociedade ao seu redor. Nesse sentido, 
[...] considera-se pessoa surda aquela que, por ter perda auditiva, compreende e interage com o mundo por meio de experiências visuais, manifestando sua cultura principalmente pelo uso da Língua Brasileira de Sinais - Libras. Parágrafo único. Considera-se deficiência auditiva a perda bilateral, parcial ou total, de quarenta e um decibéis $(\mathrm{dB})$ ou mais, aferida por audiograma nas freqüências de $500 \mathrm{~Hz}, 1.000 \mathrm{~Hz}, 2.000 \mathrm{~Hz}$ e $3.000 \mathrm{~Hz}$ (BRASIL, 2005).

Cabe expor que existe diferenciação entre o indivíduo que se declara com deficiência auditiva e aquele que se posiciona enquanto pessoa surda. O sujeito com deficiência auditiva geralmente é usuário de aparelho auditivo, possui resquícios auditivos e se comunica pela língua portuguesa, sendo inclusive oralizada; já a pessoa surda é usuária majoritariamente da Língua Brasileira de Sinais (LIBRAS), podendo usar ou não aparelho auditivo, possui perda auditiva de grau severo ou profundo, pode ser filho de pais ouvintes e/ou surdos e geralmente está vinculado a comunidade surda (MOURA, 2014). O grande divisor diz respeito à sua imersão e ação junto a população surda por meio dos aspectos culturais.

Ao pensar na criança surda, há um embate sobre o lugar em que ela deva ser escolarizada. O posicionamento da Política Nacional da Educação Especial na Perspectiva da Educação Inclusiva (2008, p.11) referenda que a matrícula dos estudantes com deficiência seja realizada em escola regular. Nessa política está posto inclusive que, "devido à diferença lingüística, orienta-se que o aluno surdo esteja com outros surdos em turmas comuns na escola regular", dando ênfase aos aspectos da educação inclusiva e a luta pela inclusão escolar.

Os pressupostos das políticas brasileiras de educação inclusiva ressaltam que todos os estudantes com ou sem deficiência devem aprender em conjunto, em uma mesma escola. Assim, o conhecimento acadêmico/escolar deve ser flexibilizado, para que a diversidade de estudantes tenha acesso aos saberes científicos, sistematizados e adquiridos pela humanidade ao longo do tempo (SAVIANI, 2009; 2013). Para tanto, a escola precisa se reconhecer como inclusiva e seus agentes necessitam optar por incluir a todos, visto que a mudança de paradigma implica uma reforma em termos de: formação, currículo acessível, avaliação adequada a 
cada estudante e diversificação na realização das atividades em sala de aula. Ropoli et al. (2010) acrescentam que:

\begin{abstract}
A escola comum se torna inclusiva quando reconhece as diferenças dos alunos diante do processo educativo e busca a participação e o progresso de todos, adotando novas práticas pedagógicas. Não é fácil e imediata a adoção dessas novas práticas, pois ela depende de mudanças que vão além da escola e da sala de aula. Para que essa escola possa se concretizar, é patente a necessidade de atualização e desenvolvimento de novos conceitos, assim como a redefinição e a aplicação de alternativas e práticas pedagógicas e educacionais compatíveis com a inclusão (ROPOLI et al. 2010, p.9).
\end{abstract}

As mudanças, por mais complexas que sejam, geram frutos que potencializam a educação de qualidade tão buscada no sistema educacional brasileiro. Factualmente, o estudante surdo necessita ser aceito como aprendiz dentro da escola regular, independente de suas peculiaridades linguísticas, não apenas em razão do que está prescrito em Lei, mas também por conta da função social que a escola deve desempenhar, quanto à formação de pessoas para atuar criticamente em sociedade. A escola dita inclusiva deve atender a todos, quer seja a pessoa com deficiência auditiva, pessoa surda, ou com qualquer outra característica biopsicossocial.

A educação inclusiva abrange todas as pessoas, independente desta possuir deficiência ou não; já o conceito de inclusão escolar diz respeito exclusivamente aos estudantes, público-alvo da educação especial, e se configura em acesso, participação, permanência e aprendizagem dos conteúdos acadêmicos (BRASIL, 2015). Sem essas ações organizadas sistematicamente pela escola, não é possível dizer que algum estudante está incluso na escola regular. Há muitos contextos sociais que mencionam a escola regular da atualidade como escola inclusiva, isso por atender aos estudantes com deficiência matriculados. Na maioria das vezes, esse atendimento conta apenas como acesso a sala de aula e não com ações que possibilitam a aprendizagem de conteúdos acadêmicos, tais como leitura e escrita. Barbosa (2018), Mendes (2017) e Caiado (2009) explicitam que a construção da ideia de inclusão escolar imposta diz respeito ao 
acesso, permanência e aprendizagem dos conteúdos acadêmicos. Contudo, o modelo de escolarização preconizada e realizada na prática social, relacionada ao movimento da inclusão escolar, ainda está em construção no Estado brasileiro e apresenta historicamente grandes desafios, haja vista a garantia do acesso, embora esse acesso nem sempre acompanhe ações de permanência e de aprendizagem no interior da escola regular. Certamente, há um consenso nos escritos da legislação brasileira, quanto à inclusão e educação inclusiva,

Porém, em países marcados com tão grandes desigualdades sociais, como o Brasil, os direitos sociais precisam ser entalhados em lei para que a maioria da população que é pobre, ou muito pobre, tenha canais de luta pela garantia de seu direito à vida e à dignidade (CAIADO, 2009, p. 332).

Nesse sentido, a comunidade surda tem levantado discussão sobre a matrícula em escola ou classe bilíngue que privilegie a comunicação por meio da LIBRAS.

Entende-se como Língua Brasileira de Sinais - Libras a forma de comunicação e expressão, em que o sistema lingüístico de natureza visual-motora, com estrutura gramatical própria, constituem um sistema lingüístico de transmissão de idéias e fatos, oriundos de comunidades de pessoas surdas do Brasil (BRASIL, 2002).

A LIBRAS é utilizada como língua principal, forma de comunicação e expressão na escola ou classe bilíngue, a língua portuguesa é empregada como modalidade escrita e ambas são utilizadas como língua de instrução em todo o processo educativo (BRASIL, 2005). Na escola bilíngue, em que há matrícula de estudantes surdos e ouvintes, os diferentes professores, das diversas áreas do conhecimento, devem estar "[...] cientes da singularidade lingüística dos alunos surdos, bem como com a presença de tradutores e intérpretes de Libras - Língua Portuguesa" (BRASIL, 2005, p. 07).

A escola ou classe bilíngue ainda não é realidade em todas as cidades brasileiras, embora haja um avanço em projetos educacionais para a abertura delas. Lacerda, Albres e Drago (2013, p. 65) realizaram estudo sobre as políticas para educação bilíngue com ênfase em escolas 
municipais do estado de São Paulo, que possui escolas organizadas na perspectiva da educação inclusiva bilíngue, e concluíram que há possibilidade:

[...] de uma educação plural, entendendo que pessoas com surdez têm diversas necessidades e condições, e que a inclusão social desses sujeitos, no que tange à educação, pode dar-se com diferentes roupagens (LACERDA; ALBRES; DRAGO, 2013, p. 65).

Assim, não há necessidade de se pensar em uma escola homogênea que acomode a todos os estudantes, há de se prever escolas que atendam as particularidades das diversidades da população estudantil brasileira.

Cada sujeito é único e necessita de diferentes estratégias para ascender no sistema educacional. Não há como pensar em educação para todos disponibilizada de forma engessada, inclusive quando pensada para os estudantes surdos, visto que suas peculiaridades fomentam novos desafios no ambiente escolar. Para que o estudante se desenvolva, ele precisa de interação com seus pares, com pessoas que utilizem sua língua.

Uma escola dita inclusiva para essa população necessita de pessoas que falem e ensinem na língua majoritária do estudante. Há de se considerar, portanto, o respeito a condição linguística, cultural e curricular dos estudantes surdos (SANTOS; GURGEL, 2014). O exposto nos decretos e leis brasileiras ao longo dos últimos anos contribui para uma possível mudança na visão da comunidade escolar, no que diz respeito à prescrição de estrutura e profissionais habilitados para o ensino das pessoas surdas (BRASIL, 2002; 2005; 2010; 2015). Nesse viés, o estudo em questão visa a analisar o prescrito nos dispositivos legais, referente à educação para o indivíduo surdo, desvelando os apoios e os profissionais que deverão estar envolvidos no ambiente educacional direcionado à população surda.

\section{METODOLOGIA}

Este estudo tem caráter bibliográfico e parte de pesquisa documental para investigação dos fatos. Segundo Gil (2002), a pesquisa bibliográfica é desenvolvida com base em material já elaborado, enquanto a pesquisa documental se utiliza de documentos como fonte de dados. Gil (2011) 
conceitua documento como arquivos escritos, que tem por objetivo esclarecer algum conteúdo e contribuir de alguma forma para a investigação de determinado fato ou fenômeno. Os documentos variam segundo suas fontes, podendo ser de arquivos públicos ou particulares (MARCONI: LAKATOS, 2012). Os documentos públicos e oficiais, geralmente, constituem-se de fontes fidedignas de dados e oferecem conhecimentos objetivos da realidade. A pesquisa documental utiliza documentos como fonte de dados. Nestes tipos de documentos, há uma gama de arquivos. Dessa forma, compete ao pesquisador julgar os tipos de documentos adequados às suas finalidades, cabendo inclusive a ele selecionar aquilo de maior interesse para assim interpretar e utilizar. Chizzotti $(2005$, p. 18) salienta que "quem inicia uma pesquisa não pode dispensar as informações documentadas", visto que por meio dos documentos há possibilidade de conhecer a situação histórica e atual do problema que se pretende investigar.

Para este estudo, utilizamos como documentos os dispositivos legais que se relacionam diretamente a pessoa surda, quais sejam: Lei $N^{0} 10.436$ (2002); Decreto No 5.626(2005); Lei No 12.319 (2010); e, Lei No 13.146 (2015).

A análise de dados foi realizada por meio da análise de conteúdo, do tipo temático e ocorreu em três etapas: pré-análise, exploração dos dispositivos legais elencados e interpretação, buscando observar e analisar os pontos relacionados aos objetivos do estudo (BARDIN, 2009).

\section{RESULTADO E ANÁLISE DE DADOS}

O Estado brasileiro prescreveu inúmeros dispositivos legais que relacionam-se diretamente a luta das pessoas com deficiência e/ou seus responsáveis na busca do cumprimento de seus direitos, tais como educação, saúde, entre outros. Com entraves sociais, houve a conquista de Leis e Decretos que mencionam e reafirmam esses direitos. Assim, foi necessária a reafirmação de direitos em dispositivos legais.

Neste estudo, analisaremos os documentos com referência à pessoa surda, considerando questões educacionais, uma vez que educação é 
direito inalienável para todo e qualquer ser humano. Os dispositivos legais analisados foram: Lei $N^{\circ}$ 10.436, de 24 de abril de 2002, que dispõe sobre a Língua Brasileira de Sinais - Libras e dá outras providências; Decreto № 5.626 , de 22 de dezembro de 2005, que regulamenta a Lei no 10.436, de 24 de abril de 2002, que dispõe sobre a Língua Brasileira de Sinais - Libras e o art. 18 da Lei no 10.098, de 19 de dezembro de 2000; Lei $N^{\circ} 12.319$, de $1^{\circ}$ de setembro de 2010, que regulamenta a profissão de Tradutor e Intérprete da Língua Brasileira de Sinais - LIBRAS; Lei No 13.146, de 6 de julho de 2015, que institui a Lei Brasileira de Inclusão da Pessoa com Deficiência (Estatuto da Pessoa com Deficiência).

Os documentos mencionados complementam-se e norteiam as ações relacionadas à pessoa surda nos diversos ambientes, inclusive aqueles que não dizem respeito à esfera educacional. Cabe salientar que trataremos de cada um deles de forma separada, buscando observar as questões relacionadas ao âmbito educacional. Muitos deles tiveram artigos e parágrafos atualizados e substituídos pelas leis subsequentes, aqui expostas.

De forma pontual, é possível explicitar que os dispositivos legais (BRASIL, 2002; 2005; 2010; 2015a) possuem algumas similaridades, tais como: conceituação sobre quem é a pessoa surda e a pessoa com deficiência auditiva; explicitação direta sobre o que é a LIBRAS e sua constituição como língua; menção a obrigatoriedade do intérprete de LIBRAS nos ambientes educacionais e sociais, bem como do instrutor bilíngue na esfera educacional nos diversos níveis e modalidades educacionais. Em termos de formação desses profissionais, os dispositivos afirmam que a certificação de proficiência em LIBRAS é obrigatória e pode ser obtida por meio de exame promovido pelo Ministério da Educação e/ou por meio de curso de graduação em Letras/LIBRAS. Destacam ainda a prioridade do sujeito surdo em desenvolver as funções prescritas nos documentos.

Cabe ressaltar que os direitos vinculados às leis e decretos estão escritos, contudo há uma grande lacuna entre o prescrito e o efetuado pela sociedade brasileira como um todo, inclusive no que diz respeito à educação. Giron (2008, p. 18) alerta que "as políticas públicas foram e são 
implementadas, reformuladas ou desativadas de acordo com as diferentes formas, funções e opções ideológicas assumidas pelos dirigentes do Estado, nos diferentes tempos históricos". Ao longo dos anos, as políticas públicas sofreram inúmeras alterações, e, por vezes, não responderam às necessidades da população, mas sim à visão ideológica dos dirigentes do Estado. Por isso, a necessidade de problematizar e analisar os dispositivos legais. Vejamos a seguir cada dispositivo elencado e alguns apontamentos sobre eles.

\section{Lei $\mathrm{N}^{\circ}$ 10.436, de 24 de abril de 2002}

Esta lei é um marco no que diz respeito aos dispositivos legais relacionadas à pessoa surda. Por intermédio dela, é que a LIBRAS foi reconhecida como língua, sendo inclusive "reconhecida como meio legal de comunicação e expressão"(BRASIL, 2002). A partir desse momento, a LIBRAS foi certificada e passou a ser utilizada e difundida em todo território brasileiro, disponibilizando assim uma maior interação entre a comunidade surda brasileira e a sociedade como um todo. Anteriormente, tínhamos um cenário em que a LIBRAS era vista como uma linguagem exclusivamente dos surdos, inclusive alguns linguistas sequer visualizavam a LIBRAS como língua, fato que dificultava sua aceitação e utilização pela sociedade como um todo. Dessa forma, não havia difusão, nem busca de conhecimentos pela LIBRAS, mas, após os dispositivos legais, isso se modificou e tem se modificado paulatinamente.

Lacerda (2007) tem realizado inúmeros estudos a respeito da LIBRAS, no que concerne à sua difusão e utilização pela sociedade brasileira. Ao partir de uma escola regular brasileira com estudantes surdos regularmente matriculados e com tradutor/intérprete de LIBRAS no quadro de funcionários, a autora observou que alunos surdos e ouvintes estabeleciam trocas linguísticas por intermédio da LIBRAS e que, inclusive, havia respeito pela condição linguística do estudante surdo e interesse em conhecer a sua realidade, quanto aos aspectos culturais e linguísticos. Nesse sentido, é possível depreender que não apenas os profissionais buscavam conhecer a 
LIBRAS, mas também a população de estudantes. No estudo supracitado, foi ressaltado que o não domínio da LIBRAS pela comunidade escolar lestudantes, professores, coordenadores, gestão, recursos humanos e familiares) dificulta a interação entre os estudantes, bem como a inclusão deste no ambiente escolar.

É preponderante ressaltar que ainda há escolas brasileiras que sequer possuem o intérprete de LIBRAS em seu quadro e que, nesses casos, muitos estudantes surdos frequentam a escola dita inclusiva sem ter acesso ao conteúdo acadêmico em LIBRAS (BARBOSA; VITORINO; DIAS, 2016). Tais aspectos implicadores do processo de aprendizagem dos estudantes surdos transformam a escola que deveria ser inclusiva em um espaço possível de exclusão. O Estado brasileiro possui inúmeras pluralidades econômicas e sociais e, por vezes, os estados e municípios não se responsabilizam na contratação de intérprete e de pessoas capcitadas no atendimento ao estudante surdo. Barbosa, Vitorino e DIAS (2016, p. 189) afirmam que nem todos os professores [...] "tem formação específica e não busca se capacitar para atender o público surdo". Há importância do conhecimento da LIBRAS pela comunidade escolar. A Lei № 10.436 explicita que a LIBRAS não substitui a modalidade escrita da língua portuguesa (BRASIL, 2002).

Nesse sentido, a comunidade surda, além de se comunicar em LIBRAS, deverá buscar também conhecimentos da língua portuguesa no que tange à leitura e escrita. Para que isso ocorra, faz-se necessária a presença do instrutor surdo no cotidiano escolar, bem como um AEE de qualidade que oferte o ensino de LIBRAS e de língua portuguesa para estudantes surdos.

Conforme Brasil (2011), o AEE para esses estudantes deve ocorrer de forma complementar, em horário contrário a escolarização e duas vezes por semana. Contudo, esse modelo de serviço não supre as carências educacionais dos estudantes, haja visto o pouco tempo e, por vezes, o baixo nível de conhecimento dos professores do AEE, já que nem todos possuem conhecimento sólido da língua de sinais.

Ainda segundo Brasil (2011), a formação dos professores que atuam no AEE é generalista na área da Educação Especial e a orientação é para que 
eles devam disponibilizar atendimento a todos os estudantes com deficiência (visual, auditiva, intelectual, física), com transtorno do espectro autista e com altas habilidades/superdotação. Em Brasil (2008), o professor do AEE "deve ter como base da sua formação, inicial e continuada, conhecimentos gerais para o exercício da docência e conhecimentos específicos da área [de educação especial]". Mas cada município flexibiliza a exigência da formação desse profissional e sua atuação, bem como algumas ações da Educação Especial, mesmo tendo como diretriz o que está expresso na legislação nacional.

Em se tratando de AEE, Mendes e Malheiro (2012) afirmam que 0 modelo único do AEE centrado na Sala de Recursos Multifuncionais (SRM) não tem atendido a gama de estudantes que nela adentram. Os ambientes das SRM são dotados de inúmeros materiais didáticos abastecidos pelo Estado, advindos do Programa de Implantação de Salas de Recursos Multifuncionais (BRASIL, 2007) e de recursos financeiros provenientes do Fundo de Manutenção e Desenvolvimento da Educação Básica e de Valorização dos Profissionais da Educação (FUNDEB), devido à centralidade de ações e investimentos desse ambiente como atendimento prioritário na política de educação especial contemporânea (BAPTISTA, 2015). Mas convém lembrar que, frequentemente, as escolas públicas brasileiras apresentam dificuldades para gerir esse recurso, em virtude das inúmeras carências existentes. Saviani (2009), em inúmeros momentos de sua obra, discutiu a necessidade de ampliação de recursos orçamentários, a partir da realização de novos cálculos e de repasses financeiros para a manutenção da educação brasileira. Cabe ainda lembrar que essa questão financeira não diz respeito apenas à educação de estudantes surdos, mas a toda diversidade de estudantes, que adentra a escola regular e necessita de um olhar diferenciado para que permaneça na escola e adquira conhecimentos acadêmicos.

Uma possibilidade real de educação de qualidade para estudantes surdos seria uma parceria colaborativa entre professor do AEE, professor de sala de aula e ações do instrutor de LIBRAS. Um planejamento de ações 
conjuntas entre esses profissionais poderia ampliar o nível de flexibilidade e adequações curriculares para, assim, acontecer a ascensão acadêmica para o estudante. É necessária a busca de soluções para que essa parceria preconizada aconteça, visto que toda a comunidade escolar só tem a se beneficiar com isso. Baptista $(2015$, p.26) aponta que:

Será necessário que o debate contemporâneo e a capacidade de gestão delimitem com maior clareza $\circ$ conjunto de iniciativas/expectativas dirigidas a esses profissionais que passam a ter uma ação de extrema importância no atual momento histórico.

A necessidade do aprendizado de LIBRAS pelos professores atuantes em sala de aula é uma realidade consolidada, tanto que a Lei $N^{\circ} 10.436$ apresenta a obrigatoriedade do ensino da LIBRAS nos cursos de formação em nível superior de ensino. Nela salienta-se que:

Art. $4^{\circ} \mathrm{O}$ sistema educacional federal e os sistemas educacionais estaduais, municipais e do Distrito Federal devem garantir a inclusão nos cursos de formação de Educação Especial, de Fonoaudiologia e de Magistério, em seus níveis médio e superior, do ensino da Língua Brasileira de Sinais - Libras, como parte integrante dos Parâmetros Curriculares Nacionais - PCNs, conforme legislação vigente (BRASIL, 2002).

A partir de 2002, todo e qualquer estudante a ser licenciado passou a ter acesso obrigatório a disciplina de LIBRAS, tanto nas faculdades públicas quanto nas privadas. Trata-se de um avanço na formação inicial do professor para conhecer as particularidades da pessoa surda e sua condição cultural, bem como a língua de sinais. Esses conhecimentos potencializam a inclusão escolar desses estudantes. É importante ressaltar que o decreto $N^{\circ} 5626$ de 2005 também trouxe os aspectos relacionado ao ensino da LIBRAS como disciplina curricular em diversos cursos de ensino superior, como veremos a seguir.

\section{Decreto $\mathrm{N}^{\circ} 5.626$, de 22 de dezembro de 2005}

Este decreto traz inúmeras questões que ampliaram a efetivação dos direitos relacionadas à pessoa surda. Ele caracteriza, inclusive, quem é o 
surdo e quem é a pessoa com deficiência auditiva. Nesse dispositivo legal, a ênfase recai sobre a formação do professor de LIBRAS e do instrutor de LIBRAS, bem como sobre a disciplina de LIBRAS nos cursos profissionalizantes e de ensino superior. O decreto reafirma o acesso das pessoas surdas à educação, dando-lhes garantia do direito à educação, e ainda faz menção ao papel do poder público e das empresas, as quais detêm concessão ou permissão de serviços públicos no apoio ao uso e difusão da LIBRAS (BRASIL, 2005).

O acesso e a garantia da educação da/as pessoas surdas envolvem inúmeras necessidades, principalmente no que tange à formação de profissionais para atuar de forma direta com essa população. O conhecimento da LIBRAS é obrigatoriedade, bem como o conhecimento das particularidades do sujeito e da comunidade surda. Nesse sentido, o decreto $N^{\circ} 5.626$ de 2005 prevê inúmeros requisitos para a formação, inclusive enfatiza a prioridade dos surdos em cursos de formação profissional, bem como na atuação do campo de trabalho. Vejamos, a seguir, as especificidades da formação dos profissionais de LIBRAS:

\begin{abstract}
Art. 4o A formação de docentes para o ensino de Libras nas séries finais do ensino fundamental, no ensino médio e na educação superior deve ser realizada em nível superior, em curso de graduação de licenciatura plena em Letras: Libras ou em Letras: Libras/Língua Portuguesa como segunda língua [...] Art. 60 A formação de instrutor de Libras, em nível médio, deve ser realizada por meio de: I - cursos de educação profissional; II - cursos de formação continuada promovidos por instituições de ensino superior; e III - cursos de formação continuada promovidos por instituições credenciadas por secretarias de educação (BRASIL, 2005).
\end{abstract}

Conforme o decreto mencionado, as formações deveriam ter sido realizadas entre os anos de 2005 e 2015 com a criação de cursos de ensino superior de Letras/LIBRAS, caso não fosse possivel obter tal formação em nível superior os profissionais que fossem atuar diretamente com a Libras poderiam apresentar o certificado de proficiência em LIBRAS, obtido por meio de exame de proficiência promovido pelo Ministério da Educação, denominado usualmente de Prolibras. Esse exame "[...] deve avaliar a 
fluência no uso, o conhecimento e a competência para o ensino dessa língua" (BRASIL, 2005). Na atualidade, houve a consolidação do curso de Letras/LIBRAS em diversas universidades brasileiras, na modalidade presencial e na modalidade de educação à distância, e o exame do Prolibras deixou de ser aplicado anvalmente. Ainda há necessidade de profissionais que dominem a LIBRAS e possua formação. O governo brasileiro tem buscado ampliar vagas em nível superior para a formação inicial desses profissionais, isso porque:

Há necessidade de profissionais qualificados e/ou capacitados com metodologias e estratégias que possam atender aos alunos surdos adequadamente, já que a inclusão não é somente matricular alunos surdos nas escolas comuns, incluir é buscar estratégias que possam atender a todos e que essas estratégias metodológicas façam sentido para aqueles que têm deficiência (BARBOSA; VITORINO; DIAS, 2016, p.190).

O uso da LIBRAS potencializa a inclusão escolar dos surdos nos quesitos permanência, participação e aprendizagem dos conteúdos acadêmicos. A metodologia tradicional utilizada nas escolas regulares distancia o acesso ao conhecimento para toda a população de estudantes que adentram a escola, visto que exposições orais não são acessíveis a todos. Essa metodologia se relaciona a pedagogia tradicional. Saviani $(2013$, p.100) expõe que:

Se nós pensarmos uma sala de aula típica da pedagogia tradicional, vamos encontrar um conjunto grande de carteiras diante de uma mesa que ocupa posição destacada, e que é a mesa do professor. As carteiras na sala típica da pedagogia tradicional são fixas e voltadas todas para determinado ponto onde se encontra 0 professor. Trata-se, pois, de uma escola cujo centro é o professor, a quem cabe tomar as iniciativas e direcionar o processo pedagógico. Consequentemente, a sala de aula própria dessa escola foi pensada e programada fisicamente para que os alunos prestem atenção nas explicações do professor. Por isso é uma sala de aula silenciosa, de paredes opacas.

Esse modelo dificulta o acesso ao saber pelos estudantes surdos, que não conseguem compreender o português falado e, por vezes, têm dificuldades na língua escrita. A língua natural do surdo é a LIBRAS e o português funciona como segunda língua, na qual vivencia dificuldades de 
compreensão e domínio. Mesmo com o passar dos anos de escolarização, ainda há estudantes surdos que apresentam dificuldades na escrita e leitura do português. A escola dita inclusiva e os profissionais que atuam nela precisam inovar para atender a diversidade de estudantes que cotidianemente adentram a escola brasileira. Esses aspectos devem ser apresentados na formação dos professores, desde o início da graduação e permear os aspectos da formação continuada.

Quanto à formação inicial, o decreto $n^{\circ} 5626$, ao expor sobre a criação de cursos para profissionais habilitados atuarem com a comunidade surda, reafirma o mencionado na Lei n 10.436 e implementa as observações necessárias quanto ao acesso e auxílio a permanência das pessoas surdas nas instituições educacionais. $O$ artigo 14 do referido decreto salienta que:

As instituições federais de ensino devem garantir, obrigatoriamente, às pessoas surdas acesso à comunicação, à informação e à educação nos processos seletivos, nas atividades e nos conteúdos curriculares desenvolvidos em todos os níveis, etapas e modalidades de educação, desde a educação infantil até à superior (BRASIL, 2005).

Essa garantia reafirma o preconizado nas políticas brasileiras de educação especial, quanto à flexibilização e adequação curricular. Além do acesso à informação e conteúdo em LIBRAS, o mesmo capítulo do decreto trata do AEE para os estudantes surdos. De forma pontual, esse assunto foi discutido anteriormente nesse artigo, mas é importante mencionar que esse serviço é "compreendido como o conjunto de atividades, recursos de acessibilidade e pedagógicos organizados institucional e continuamente" e deve ser realizado preferencialmente na Sala de Recursos Multifuncionais, as quais "são ambientes dotados de equipamentos, mobiliários e materiais didáticos e pedagógicos para a oferta do atendimento educacional especializado" (BRASIL, 2011). Esse serviço, segundo o prescrito no conjunto de normas legais, objetiva contribuir para a escolarização do público-alvo da educação especial, integrando a proposta pedagógica da escola, com vistas a garantir a inclusão (o acesso, 
a participação, a permanência e a aprendizagem desses estudantes) no ambiente escolar.

O AEE funciona em ambiente de escola regular com um professor que possui formação especifica para atuar na função. No que diz respeito aos estudantes surdos, o serviço prestado no AEE deve complementar a escolarização, nunca substituíla. Tal ação diz respeito ao ensino de habilidades acadêmicas para o estudante e para o ensino da Libras. Cabe salientar que a política possibilita o acesso à escola e ao AEE, mas nem sempre desenvolve ações diretas para permanência e aprendizagem dos conteúdos acadêmicos. Não há referência sobre tais questões nos diversos documentos legais, por mais que os professores saibam que deve complementar o ensino e trabalhar com a Libras, não há prescrição de conteúdos ou de ações especificas a serem realizadas.

Após inúmeros embates e lutas ao longo da história, a participação do estudante surdo na escola regular e no AEE foi conquistada, materializada, mesmo que de forma pontual. Na atualidade, há busca de mudanças quanto à escolarização, porque a participação na escola regular e no AEE não tem suprido a necessidade dos estudantes surdos (LACERDA, ALBRES; DRAGO, 2013).

O decreto de 2005 ainda trata da classe e/ou escola bilíngue para os estudantes surdos. Segundo o artigo 22 desse decreto:

As instituições federais de ensino responsáveis pela educação básica devem garantir a inclusão de alunos surdos ou com deficiência auditiva, por meio da organização de: I - escolas e classes de educação bilíngüe, abertas a alunos surdos e ouvintes, com professores bilíngües, na educação infantil e nos anos iniciais do ensino fundamental; II - escolas bilíngües ou escolas comuns da rede regular de ensino, abertas a alunos surdos e ouvintes, para os anos finais do ensino fundamental, ensino médio ou educação profissional, com docentes das diferentes áreas do conhecimento, cientes da singularidade lingüística dos alunos surdos, bem como com a presença de tradutores e intérpretes de Libras - Língua Portuguesa. $\S$ 10 São denominadas escolas ou classes de educação bilíngüe aquelas em que a Libras e a modalidade escrita da Língua Portuguesa sejam línguas de instrução utilizadas no desenvolvimento de todo o processo educativo (BRASIL, 2005). 
Após esse decreto, a inclusão dos estudantes surdos, diferentemente dos outros estudantes público-alvo da educação especial, deveria acontecer em escola diferenciada, sendo essa a classe ou escola bilíngue, já que esses estudantes necessitam de profissionais capazes de instruírem em sua língua de domínio: a LIBRAS. Nesse ambiente deve haver tradutor e intérprete de LIBRAS, professores bilíngues, instrutor surdo e conhecimento (por parte da direção, funcionários e demais professores e estudantes) da condição linguística dos estudantes surdos, viabilizando, assim, comunicação, informação e interação, entre todos (BRASIL, 2005).

No movimento da inclusão escolar que outrora era apregoado para os estudantes surdos, a responsabilidade relacionava-se à escola, explicitando a necessidade de reestruturar o sistema educacional e o processo de escolarização para incluir todos os estudantes. Esse contexto historicamente foi percebido como avanço, contudo houve ênfase na educação como redentora dos males sociais (JANNUZZI, 2004). Jannuzzi (idem) expõe que é possível pensar a educação como influência no processo de transformação social, pois:

Supõe assumir a responsabilidade da escola na sua complexidade, e, portanto, implica que os agentes escolares (diretor, supervisor, professor, funcionários em geral) estejam atentos às dificuldades de cada aluno e procurem pelo aprofundamento dos conhecimentos historicamente acumulados, pela percepção clara da realidade social e individual de cada um, por meio de métodos e técnicas adequados que the facilitem a apropriação do saber realmente necessário ao tempo e ao lugar (JANNUZZI, 2004, p. 22).

Entender o passado por meio da inclusão escolar potencializa conhecer $O$ presente e estudar possíveis avanços frente aos desafios inerentes à educação das pessoas surdas. É preponderante problematizar que a escolarização das pessoas surdas se tornará real, permitindo que o prescrito da classe ou escola bilíngue seja uma escolha possível dos estudantes surdos.

Outro aspecto importante desse decreto é o estímulo do aprendizado da LIBRAS pela sociedade, tanto para o desenvolvimento da comunicação 
com a comunidade surda como também para auxiliar na prestação de serviço. Há inclusive referência à capacitação de cinco por cento de servidores, funcionários e empregados para uso e interpretação da LIBRAS (BRASIL, 2005). Tal medida beneficia a comunidade surda, como também estimula a sociedade a buscar os conhecimentos relacionados a LIBRAS.

Posterior a esse decreto, o poder público referendou uma lei específica sobre o exercício profissional do tradutor e intérprete de LIBRAS. Vejamos a seguir.

\section{Lei $\mathrm{N}^{\circ} 12.319$, de $1^{\circ}$ de setembro de 2010}

Esta lei foi publicada com o objetivo de regulamentar o exercício da profissão de Tradutor e Intérprete da LIBRAS. Antes dessa legislação, muitos profissionais que atuavam com a língua de sinais não possuíam formação e também não tinham domínio da língua, ocasionando marginalização da população de pessoas surdas que nem sempre tinha acesso adequado às informações em nível educacional e social. Havia intérpretes que atuavam nas escolas apenas por conhecerem alguns sinais da LIBRAS e outros que por serem familiares de pessoas surdas adentravam na profissão.

Diante dessas questões e com o avanço das políticas educacionais relacionadas à comunidade surda, houve ampliação da necessidade do tradutor e intérprete da LIBRAS que realmente conhecessem a língua e a dominassem. Inicialmente, esse profissional foi requerido nos ambientes educacionais em nível de educação básica e ensino superior, sendo que atualmente é requerido nos diferentes ambientes sociais, quer sejam de âmbito público ou privado.

A lei aqui analisada explicita que "o tradutor e intérprete terá competência para realizar interpretação das 2 (duas) línguas de maneira simultânea ou consecutiva e proficiência em tradução e interpretação da Libras e da Língua Portuguesa" (BRASIL, 2010). Assim, o profissional estará apto para traduzir a fala de um ouvinte (usuário da língua oral), como também a fala da pessoa surda (Usuária de LIBRAS). 
A formação desse profissional teve inúmeros debates em dispositivos legais (BRASIL, 2002; 2005; 2010) e em diferentes níveis da sociedade, inclusive na comunidade surda. Um avanço desses embates foi a Lei № 12.319 que especifica e enfatiza as questões, ao afirmar que:

A formação profissional do tradutor e intérprete de Libras - Língua Portuguesa, em nível médio, deve ser realizada por meio de: I - cursos de educação profissional reconhecidos pelo sistema que os credenciou; II - cursos de extensão universitária; e III - cursos de formação continuada promovidos por instituições de ensino superior e instituições credenciadas por Secretarias de Educação (BRASIL, 2010).

A formação do tradutor e intérprete de LIBRAS pode-se dar em diversas instâncias. Há inclusive universidades federais fornecendo formação de qualidade para esse profissional. Para esse profissional, é requerido alto nível de conhecimento relacionado à LIBRAS e à cultura surda, bem como um alto teor de rigor técnico, visto que por intermédio desse profissional o indivíduo surdo transmite e assimila muitas informações necessárias à sua atuação como cidadão crítico e autônomo. Mas, na atualidade, ainda há embates para a obediência dessa lei no ambiente educacional. Factualmente, há distância substancial entre o conhecimento apresentado nas políticas públicas e a vida cotidiana (CAIADO, 2009).

Cinco anos após esse decreto, houve a publicação da Lei № 13.146 (2015). Nela são expostas diferentes informações e direitos relacionados às pessoas com deficiência, inclusive os surdos. Vejamos, no decorrer desse texto, o que ela expõe.

\section{Lei $N^{\circ} 13.146$, de 6 de julho de 2015}

A Lei Brasileira de Inclusão da Pessoa com Deficiência expõe inúmeros aspectos relacionadas à pessoa com deficiência. Inicialmente, a referida lei explicita quem são os sujeitos público-alvo, conceitua alguns termos relacionados ao corpo da legislação e expõe questões relacionadas aos diversos direitos das pessoas com deficiência. 
A lei é extensa e possui 127 artigos que abarcam inúmeros aspectos, que se relacionam diretamente a pessoa com deficiência. Um grande avanço trazida por essa lei é a questão da deficiência ser avaliada e definida por aspectos biopsicossociais, associadas à Classificação Internacional de Funcionalidade, Incapacidade e Saúde (CIF) que advêm da Organização Mundial de Saúde (OMS). O modelo apregoado pela CIF relaciona-se ao modelo biopsicossocial. Esse modelo "[...] avança no sentido de incorporar outros fatores, como os psicológicos e os sociais, no processo de cuidado em saúde" (CASTRO ET AL., 2015, p.25). Nele há ênfase as potencialidades e as funcionalidades presentes em todo e qualquer ser humano, trazendo um novo olhar sobre saúde e deficiência. Nesse sentido, "a CIF aplica-se a todas as pessoas, independentemente das condições específicas de saúde, em todos os contextos físicos, sociais e culturais" (OMS, 2004, p.12). Assim, o sujeito surdo enquadra-se enquanto pessoa com deficiência, mas não é estigmatizado pelo déficit auditivo e sim pelos fatores biopsicossociais.

Por vezes, é possível observar profissionais da área da saúde rotulando e estigmatizando indivíduos por suas incapacidades, esquecendo-se de suas funcionalidades. Há ênfase nos diversos escritos da área da saúde quanto aos prejuízos e incapacidades dos indivíduos que são diagnosticados com surdez, inclusive na legislação brasileira (BRASIL, 2002). Tais aspectos paulatinamente estão sendo modificados por meio do uso da CIF. Por intermédio dessa classificação, o sujeito é notado a partir de suas potencialidades e de suas dimensões de funcionalidade associadas às múltiplas perspectivas nos níveis corporal, pessoal e social. Nela há também a descrição das incapacidades sob o olhar biopsicossocial, sendo que tais descrições não subjugam os indivíduos numa visão do que falta e sim sob um olhar da possibilidade de desenvolvimento. Caiado (2009, p. 333) explicita que, por intermédio dessa visão e do exposto na Convenção Internacional sobre os Direitos da Pessoa com Deficiência (BRASIL, 2009a), "[...] o foco da deficiência se desloca de um impedimento puramente orgânico e 
patológico e passa a ser o da existência de barreiras sociais que impedem a participação plena na vida social".

Além do evidenciado na LBI, as diretrizes brasileiras que avaliam a pessoa com deficiência no âmbito de concessão do Benefício de Prestação Continuada (BPC) ${ }^{2}$ utilizam-se de instrumento de avaliação baseado na CIF, por meio de um profissional da área médica e da assistência social (BRASIL, 2015). Assim, o surdo é beneficiado com os direitos, por meio da avaliação, e ainda o prescrito reforça a minimização de estigmas sociais quanto à sua participação em sociedade.

Ainda sobre a LBI, em seu artigo terceiro, há exposição de diversos conceitos, inclusive do que é comunicação, remetendo a LIBRAS como língua que possibilita a interação entre os cidadãos:

V - comunicação: forma de interação dos cidadãos que abrange, entre outras opções, as línguas, inclusive a Língua Brasileira de Sinais (Libras), a visualização de textos, o Braille, o sistema de sinalização ou de comunicação tátil, os caracteres ampliados, os dispositivos multimídia, assim como a linguagem simples, escrita e oral, os sistemas auditivos e os meios de voz digitalizados e os modos, meios e formatos aumentativos e alternativos de comunicação, incluindo as tecnologias da informação e das comunicações (BRASIL, 2015a).

Esse aspecto traz à tona as características da LIBRAS, enquanto língua oficial, e possibilita que o debate quanto à sua utilização esteja sempre em ascensão. Ainda sobre a língua de sinais e a educação de surdos, o capítulo 4 expõe e reafirma o que há em outras legislações brasileiras quanto ao tipo de educação que deve ser ofertada a população surda:

[...] IV - oferta de educação bilíngue, em Libras como primeira língua e na modalidade escrita da língua portuguesa como segunda língua, em escolas e classes bilíngues e em escolas inclusivas; XI formação e disponibilização de professores para o atendimento educacional especializado, de tradutores e intérpretes da Libras, de guias intérpretes e de profissionais de apoio; XII - oferta de ensino da Libras, do Sistema Braille e de uso de recursos de tecnologia assistiva,

\footnotetext{
2 Objetivo geral do BPC é acompanhar e monitorar o acesso e permanência na escola das pessoas com deficiência, beneficiárias do Benefício da Prestação Continuada da Assistência Social - BPC, na faixa etária de 0 a 18 anos, por meio da articulação das políticas de educação, saúde, assistência social e direitos humanos, favorecendo seu pleno desenvolvimento e participação social (BRASIL, 2009b, p.01).
} 
de forma a ampliar habilidades funcionais dos estudantes, promovendo sua autonomia e participação; [...] (BRASIL, 2015a).

Conforme apresentado acima, observamos que a educação bilíngue é reafirmada, bem como o interesse do poder público na formação dos profissionais que deverão atuar nela. Contudo, há abertura para que estados e municípios não implantem a educação bilíngue, em razão da lei permitir aberturas ao mencionar que a educação para surdos com a LIBRAS pode ocorrer "em escolas e classes bilíngues e em escolas inclusivas". Assim, - Estado permite a existência de escolas inclusivas, que é a forma que tradicionalmente os surdos vêm sendo escolarizados no Brasil, embora haja uma luta da comunidade surda para a efetivação da educação bilíngue em escolas e/ou classes bilíngues.

Quanto à escolarização em escola inclusiva, Barbosa, Vitorino e Dias (2016, p. 178) afirmam que "os indicadores apresentados conduzem ao empobrecimento da cultura e da comunidade surda, bem como dificultam o processo de aprendizagem no âmbito educacional dos surdos". Em razão de tais aspectos, é que a população surda vem lutando pelas classes e/ou escolas bilíngues. Em determinados momentos a LBI é um avanço e em outros retrocessos, frente aos embates realizados pela população. Lacerda, Albres e Drago (2013) advogam pela educação bilíngue e seus impactos positivos no desenvolvimento da aprendizagem de estudantes surdos e afirmam inúmeros impasses do Estado brasileiro em relação às condições de sua implantação. Em uma visão macro, é possível visualizar as questões financeiras como um dos maiores impasses frente à construção desse sistema para a população de estudantes surdos. Saviani (2009), em inúmeros momentos de suas obras, discutiu a necessidade de ampliação de recursos orçamentários, com a realização de novos cálculos e repasses financeiros para a manutenção da educação brasileira.

Por vezes, no campo educacional, é mencionado a educação como benfeitoria do Estado, repleta de avanços para todos os estudantes, quando 
na realidade o ideário neoliberal visualiza o indivíduo relacionado ao quanto ele é capaz de consumir e/ou produzir. Esse ideário:

Trata-se da crescente subordinação da educação ao econômico e da transformação da própria educação em mercadoria, quando pais e alunos passam a ser vistos como consumidores, e o conteúdo político da educação é substituído pelos direitos do consumidor (GIRON, 2008, p. 19).

Tal exposição vai ao encontro do fato de que a educação do públicoalvo da educação especial inicialmente, em nosso país, esteve à mercê do Estado e agora, por conta das pressões sociais que reivindicam seus diretos, há alguns direitos sendo materializados no cotidiano social em resposta as lutas dos movimentos sociais. Há grupos que se organizam e lutam para que todas as pessoas tenham seus direitos respeitados e, por isso, denunciam as práticas sociais de exclusão, visando garantir de dignidade ao ser humano (CAIADO, 2009).

Quanto aos direitos profissionais e a oferta de ensino, esses devem ser cumprido pelas instituições de âmbito público e privada. No caso das instituições privadas, é "[...] vedada a cobrança de valores adicionais de qualquer natureza em suas mensalidades, anvidades e matrículas no cumprimento dessas determinações" (BRASIL, 2015^). Assim, todo e qualquer surdo deverá contar com profissionais que o auxiliem no acesso e aprendizagem do conhecimento sem ter ônus financeiro. Nessa lei de 2015, há exposição inclusive da adoção de medidas quanto aos profissionais, observando-se que:

I - os tradutores e intérpretes da Libras atuantes na educação básica devem, no mínimo, possuir ensino médio completo e certificado de proficiência na Libras; (Vigência) II - os tradutores e intérpretes da Libras, quando direcionados à tarefa de interpretar nas salas de aula dos cursos de graduação e pós-graduação, devem possuir nível superior, com habilitação, prioritariamente, em Tradução e Interpretação em Libras (BRASIL, 2015a).

A formação dos tradutores e intérpretes de LIBRAS tem recebido atenção dos dispositivos legais (BRASIL, 2005; 2010) e, ao ser reafirmada em 
2010, trouxe à tona o debate e a busca pelo cumprimento nos diversos âmbitos políticos e sociais. Aparentemente, houve uma preocupação em estabelecer quem deve exercer quais funções e a formação necessária para tal. As imposições e atribuições expostas no documento acima citado são relativamente recentes e ainda não há pesquisas que mencionem seu êxito e/ou resultados na realidade.

Outro avanço citado nesta lei diz respeito aos processos seletivos em instituições públicas e privadas. Nela há exposição da adoção de cuidados referentes ao atendimento preferencial, adoção de critérios de avaliação considerando a singularidade linguística, bem como tradução do edital em LIBRAS (BRASIL, 2015a). Com a realização dessas especificações, há um aumento na possibilidade de aprovação da população surda nos diversos exames, seleções e avaliações realizadas. Tais aspectos foram pontos de entraves da comunidade surda e a adoção delas representa avanço e permite flexibilidade nas escolhas pessoais e profissionais de cada indivíduo.

Um outro ponto exposto na lei de 2015 relaciona-se ao estímulo do poder público quanto à publicação de artigos científicos em LIBRAS, possibilitando a comunidade surda o conhecimento dos recentes avanços acadêmicos nas diversas áreas do saber (BRASIL, 2015a). Consubstancialmente, o prescrito demonstra avanços que, se forem materializadas, beneficiará a todos os envolvidos. Caiado (2009) salienta que há grupos que se organizam e lutam para que todas as pessoas tenham seus direitos respeitados e, por isso, denunciam as práticas sociais de exclusão, visando garantir dignidade ao ser humano. A despeito disso, é a comunidade surda que, ao longo do tempo, lutou e ganhou inúmeros embates, resultando nos direitos expostos nos dispositivos legais analisados neste estudo.

\section{CONSIDERAÇÕES FINAIS}

Considera-se e apreende-se que houve avanço nas prescrições dos direitos relacionados às pessoas surdas. Inúmeras necessidades e solicitações da comunidade surda foram conquistadas e estão prescritas em Lei, 
auxiliando, assim, o conhecimento da sociedade como um todo sobre as especificidades dessa população, bem como no empoderamento de toda a sociedade, podendo nas diferentes instâncias governamentais lutar para efetivação do prescrito em Lei.

Como vimos no decorrer deste estudo, as legislações direcionados á população surda são diversas e dizem respeito às peculiaridades de cada indivíduo. Se outrora havia obrigação de uma educação que apontava o estudante surdo repleto de impossibilidades na escola regular, há agora o respeito a condição cultural e linguística quanto a utilização da LIBRAS e a possibilidade de inclusão da pessoa surda no ambiente educacional, dando ênfase a classe e/ou escola bilíngue. Avanços ocorrem no prescrito; no entanto, existe uma imensa lacuna entre a teoria das políticas e a prática no cotidiano.

No momento em que é lançada a política pública, ela surge como uma solução para os problemas. No entanto, quando essa é colocada em prática no cotidiano escolar e social, ela encontra diversos obstáculos. Por tais fatos, urge a necessidade de um melhor acompanhamento das políticas públicas em nível municipal e estadual. Todos os programas visam incluir o estudante e, para que isso aconteça, existe a necessidade da teoria virar ação em todos os ambientes. Há muito a avançar na sociedade brasileira, mas é a permanência das reivindicações que auxiliará a mudança da atual realidade.

\section{REFERÊNCIAS}

BAPTISTA, C. R. Educação Especial e Políticas de Inclusão Escolar no Brasil: Diretrizes e Tendências. Escolarização e deficiência: configurações nas políticas de inclusão escolar. Claudio Roberto Baptista (organizador). - São Carlos: Marquezine \& Manzini: ABPEE, 2015.

BARBOSA, M. O.; FUMES, N. L. F.; MELO JUNIOR, A. L. Acessibilidade e inclusão nos contextos do ensino superior. CAMINE: Cam. Educ. v. 4, n. 2. 2012. P. 111. 
BARBOSA, M. O.; VITORINO, A. F.; DIAS, A. B. Um contexto de inclusão escolar de estudantes surdos em escola regular no sertão alagoano. LINHAS (FLORIANÓPOLIS. ONLINE), v. 17, p. 176-192, 2016.

BARBOSA, M. O. Estudantes com Transtorno do Espectro do Autismo (TEA) na escola: desafios para a ação educativa compartilhada. 2018. 262f. Tese (Doutorado em Educação Especial) - Centro de Educação e Ciências Humanas, Universidade Federal de São Carlos, São Carlos, 2018.

BRASIL. Constituição da República Federativa do Brasil. Brasília: Imprensa Oficial, 1988.

BRASIL. Lei N 10.436, de 24 de abril de 2002. Dispõe sobre a Língua Brasileira de Sinais - Libras e dá outras providências. Diário Oficial da União, Brasília, 25 abr. 2002.

BRASIL. Decreto-Lei N ${ }^{\circ}$ 5.626, de 22 de dezembro de 2005. Regulamenta a Lei no 10.436, de 24 de abril de 2002, que dispõe sobre a Língua Brasileira de Sinais - Libras, e o art. 18 da Lei n. 10.098, de 19 de dez. 2000. Brasília, 2005.

BRASIL. Política Nacional de Educação Especial na Perspectiva da educação Inclusiva. Brasília, MEC/SEESP, 2008.

BRASIL. Decreto N 6.949, de 25 de agosto de 2009. Promulga a Convenção Internacional sobre os Direitos das Pessoas com Deficiência e seu Protocolo Facultativo. Presidência da República. Casa Civil. Brasília, 2009 a.

BRASIL. Ministério da Educação. BPC na Escola: Documento Orientador. Grupo gestor interministerial. Brasília, 2009b.

BRASIL. Resolução $\mathbf{n}^{\circ} \mathbf{4}$, de 2 de outubro de 2009. Institui Diretrizes Operacionais para o Atendimento Educacional Especializado na Educação Básica, modalidade Educação Especial. Brasília: Imprensa Oficial, 2009c.

BRASIL. Lei No 12.319, de 1 de setembro de 2010. Regulamenta a profissão de Tradutor e Intérprete da Língua Brasileira de Sinais - LIBRAS. Brasília, 2010.

BRASIL. Decreto $\mathbf{n}^{0}$ 7.611, de 17 de novembro de 2011. Dispõe sobre a educação especial, o atendimento educacional especializado e dá outras providências. Brasília, Distrito Federal, Brasil, 2011.

BRASIL. Lei N 12.796, de 4 de abril de 2013. Altera a Lei no 9.394, de 20 de dezembro de 1996, que estabelece as diretrizes e bases da educação nacional, para dispor sobre a formação dos profissionais da educação e dar outras providências. 2013. 
BRASIL. Lei $N^{\circ}$ 13.146, de 6 de julho de 2015. Institui a Lei Brasileira de Inclusão da Pessoa com Deficiência (Estatuto da Pessoa com Deficiência). Brasília, $2015 a$.

BRASIL. Portaria Conjunta MDS/INSS n² 2, de 30 de março de 2015, do Ministério do Desenvolvimento Social e Combate à Fome (MDS) e do Instituto Nacional do Seguro Social (INSS), dispõe sobre critérios, procedimentos e instrumentos para a avaliação social e médica da pessoa com deficiência para acesso ao Benefício de Prestação Continuada. Brasília: Ministério da Saúde, 2015b.

CAIADO, K. R. M. Convenção Internacional sobre os direitos das pessoas com deficiências: destaques para o debate sobre a educação. Revista Educação Especial. v. 22, n. 35, p. 329-338, set./dez. 2009, Santa Maria, 2009.

CASTRO, S. S. de. et al. O processo saúde-doença e o modelo biopsicossocial entre supervisores de um Curso de Fisioterapia: estudo qualitativo em uma universidade pública. Caderno de Educação, Saúde e Fisioterapia, v.2, n.3, 2015 , p. $23-38$.

CHIZZOTTI, A. Pesquisa em ciências humanas e sociais.7 ed. São Paulo: Cortez, 2005.

GIL, A. C. Como elaborar projetos de pesquisa. $4^{\circ}$ ed. São Paulo: Atlas, 2002.

GIL, A. C. Métodos e técnicas de pesquisa social. 6 ed. 4 reimpr. São Paulo: Atlas, 2011.

GIRON, G. R. Políticas públicas, educação e Neoliberalismo: O que isso tem a ver com cidadania? Revista de Educação PUC-Campinas, Campinas, v. 01 n. 24, p. 17-26, junho 2008.

JANNUZZI, G. M. A educação do deficiente no Brasil: dos primórdios ao início do século XXI. Campinas: Autores Associados, 2004.

LACERDA, C. F. O que dizem/sentem alunos participantes de uma experiência de inclusão escolar com aluno surdo. Rev. Bras. Ed. Esp., Marília, Mai.-Ago. 2007, v.13, n.2, p.257-280.

LACERDA, C. F.; ALBRES, N. A.; DRAGO, S. L. S. Política para uma educação bilíngue e inclusiva a alunos surdos no município de São Paulo. Educ. Pesqui. São Paulo, v. 39, n. 1, p. 65-80, jan./mar. 2013.

MARCONI, M. A.; LAKATOS, E. M. Técnicas de pesquisa: planejamento e execução de pesquisas, amostragens e técnicas de pesquisa, elaboração, análise e interpretação de dados. 7 ed. 6 reimpr. São Paulo: atlas, 2012. 
MENDES, E. G.; MALHEIRO, C. A. L. Salas de recursos multifuncionais: é possível um serviço "tamanho único" de atendimento educacional especializado? In: MIRANDA, T. G.; GALVÃO FILHO, T. A. O professor e a educação inclusiva: formação, práticas e lugares. Salvador: EDUFBA, 2012. p. 349-366.

MENDES, E. G. Sobre alunos "incluídos" ou "da inclusão": reflexões sobre o conceito de inclusão escolar. In: VICTOR, S. O.; VIEIRA, A. B.; de OLIVEIRA, I. M. (Orgs.). Educação especial inclusiva: conceituações, medicalização e políticas. Campos dos Goytacazes, RJ: Brasil Multicultural, 2017. p. 60-83.

MOURA, M. C. Surdez e linguagem. In: LACERDA, C. F.; SANTOS, L. F. (Orgs.). Tenho um aluno surdo, e agora? Introdução à Libras e educação de surdos. São Carlos: EdUFSCar, 2014. p.13-26.

OMS, Organização Mundial de Saúde. Classificação internacional de funcionalidade, incapacidade e saúde. Portugal, 2004.

ROPOLI, E. A. et al. A educação especial na perspectiva da inclusão escolar: a escola comum inclusiva. Brasília, DF: Ministério da Educação, Secretaria de Educação Especial, Fortaleza: Universidade Federal do Ceará, v. 1. 2010.

SANTOS, L. F.; GURGEL, T. M. A. O instrutor surdo em uma escola inclusiva bilíngue. In: A. C. B. LODI; C.B.F. DE LACERDA (Orgs.). Uma escola, duas línguas: letramento em língua portuguesa e língua de sinais nas etapas iniciais de escolarização. Porto Alegre: Mediação, 2014. p. 51-64.

SAVIANI, D. Escola e Democracia: teorias da educação, curvatura da vara, onze teses sobre a educação política. 41. ed. Campinas: Autores Associados, 2009.

SAVIANI, D. Pedagogia histórico-critica: primeiras aproximações. $11 \mathrm{ed}$. rev. Campinas, SP: Autores Associados, 2013.

VIGOTSKI, L. S. A formação social da mente: o desenvolvimento dos processos psicológicos superiores. Org. Michael Cole et al. Trad. José Cipolla Neto, Luis Silveira Menna Barreto, Solange Castro Afeche. 7 Ed. São Paulo: Martins Fontes, 2010.

Recebido em: 16 de julho de 2019 Aprovado em: 26 de novembro de 2019 